\title{
Huisa Veria, Elizabeth (2020). Planeamiento y evaluación. Aplicación de herramientas de gestión en unidades de instituciones culturales. Buenos Aires: Alfagrama Ediciones.
}

El funcionamiento de las unidades de información se ha reconocido en el tiempo como una actividad de vital importancia para la sociedad, pues en ellas se ha conservado, organizado y difundido el conocimiento. En la actualidad, donde la explosión de la inforación en todos los campos del saber es difícil de controlar, se aplican diversas herramientas tecnológicas para acceder de forma rápida y pertinente a la información. Su organización, para ello, debe tener una connotación ambidiestra; es decir investigar, identificar y aplicar el conocimiento, por lo cual la experiencia en el tema que se aborda debe mostrar como resultado procesos claros que conlleven a los logros de los objetivos, por lo que la evaluación permanente permitirá ajustar lineamientos y avanzar coherentemente en la propuesta organizativa.

El texto nos plantea los procesos de planificación y evaluación en un conjunto de unidades de información que tiene como una característica principal el estar integrado por instituciones culturales. La planificación previa para la elaboración de todo el proceso de gestión y las unidades de información brinda la posibilidad de tener — como menciona la autora - un punto de partida para alcanzar la organización y la evaluación. Permitirá saber, asimismo, en qué medida se ha podido con suficiencia cumplir o no los objetivos previstos; ello evidentemente servirá para corregir y establecer nuevas prioridades en nuestra organización

Así, el libro aborda con creces y suficiencia académica todo el esquema concerniente al planeamiento y la evaluación en unidades de información. Elizabeth Huisa divide el texto en tres secciones, señalando en primer término todos los conceptos relacionados con el planteamiento, sus diferentes etapas por las que tiene que circular contemplando diversas formas de planificación y las estrategias con su debida implementación. La segunda parte toca aspectos generales, sus 
modelos por región, balance Scorecard, perspectivas y aplicación. Y finaliza con una tercera sección de casuísticas elaboradas en instituciones públicas y privadas, donde nos encontramos con archivos y bibliotecas especializadas. Los casos descritos y desarrollados permiten ilustrar todo el planteamiento que realizan las bibliotecas universitarias; en tal sentido, la investigación toma además diversos planes estratégicos. En realidad, como la autora menciona, es una apuesta por llevar a la práctica la teoría investigativa y lograr objetivos que se sustenten en la experiencia laboral y, sobre todo, en la docencia universitaria. La autora introduce con luminosidad a un contenido ordenado de ítems que conllevan a comprender todos los elementos, lo que sugiere un desarrollo superlativo de conceptos que progresivamente van deviniendo en una propuesta basada en la experiencia profesional y docente, sin dejar al margen las aplicaciones prácticas de los conocimientos aplicados llevados a cabo por los propios alumnos en sus trabajos finales. Ello hace de este libro en su conjunto una lectura obligada para estudiantes y profesionales multidisciplinarios que deseen introducirse al desarrollo de planes estratégicos en sus instituciones, sobre todo en una experiencia peruana. De tal manera, este libro contribuye además a engrosar la bibliografía nacional en el área bibliotecológica.

En el esquema del libro, la autora realiza una progresión histórica de lo que ha sido el planeamiento y más concretamente la planificación estratégica a partir de conceptualizaciones de diversos autores. Con un recuento histórico, esboza la definición de lo que es el planeamiento estratégico, su importancia y sobre todo lo que se logra con su aplicación adecuada como instrumento y medida necesaria para poder realizar cambios en el entorno. Nos lleva a considerar elementos que nos permitan identificar cómo una organización puede trabajar con una misión, visión y valores que correspondan a elaborar una planificación acorde con los objetivos que se propone. Estos conceptos administrativos que maneja la autora los desarrolla en el tema de manera muy clara y detallada, lo que permite entender cuál es la base de la propuesta que elabora en su texto. Además utiliza gráficas de propuestas estratégicas como planes de acciones y desarrollo, pasando por etapas operativas analíticas y filosóficas, lo que nos conduce a 
saber qué herramientas de gestión son necesarias para elaborar estas cadenas de valor establecidas en la planificación, las actividades y los servicios que se muestran como el eje central para lograr establecer una estructura organizacional precisa. Igualmente nos muestra con imágenes de matrices Foda cómo es posible considerar factores internos y externos, fortalezas y debilidades que contribuyen a que una organización pueda desarrollarse de manera positiva o negativa, buscando minimizar los riesgos y llegando finalmente al plan que pretende alcanzar los objetivos mediante actividades y presentando recursos nuevos.

La evaluación se explica como una parte de una función administrativa que no se encuentra aislada del resto de funciones. Por el contrario, se interrelaciona y retroalimenta entre la planificación, organización, dirección y control que es fundamental para la institución. Planeamiento y evaluación. Aplicación de herramientas de gestión en unidades instituciones culturales nos conduce a un proceso donde se puede identificar los aspectos internos y externos que influyen en el desarrollo de la organización y finalmente nos adentra en la evaluación como parte de una función administrativa que no se encuentra aislada del resto de funciones. Elizabeth Huisa nos señala los conceptos de evaluación de unidades de información mediante la revisión de diversos autores que conlleva a la elección de un método de evaluación de calidad, la misma que debe de ser apropiada para conseguir el objetivo trazado. Luego nos indica que los términos y los modelos de calidad deben ceñirse a la tarea de evaluar eficazmente y nos brinda una serie de conceptos de autores que refieren a modelos de calidad en organizaciones. Se explica también los criterios para mejorar la competitividad en la organización, el liderazgo, la planificación, el enfoque de los recursos, la gestión por procesos, entre otros. Resalta también la importancia que tienen que tener los principios de la gestión en calidad y la mejora continua. Hace referencia al balance Scorecard, su definición, sus características, sus beneficios y perspectivas como un cuadro de mando integral y aplicaciones en la organización para luego establecer paralelos con los casos de universidades nacionales y particulares. Finalmente, en la última parte, la autora explica sobre la cultura de la calidad educativa y define la áreas estratégicas para los cuatro ámbitos en perspectiva: cliente, financiero, procesos 
y aprendizaje; para ello muestra ejemplos y las áreas claves de este proceso. Asimismo, señala los objetivos estratégicos y un diagrama causa-efecto que gráfica la representación de las hipótesis en la que se va a realizar la estrategia. Concluye con un mapa estratégico, indicadores y de líneas acción.

De este modo, se abren innumerables perspectivas para el análisis bibliotecológico en unidades de información. Con publicaciones de esta índole, los especialistas, bibliotecarios, documentalistas y educadores tienen en sus manos una herramienta eficaz para la planificación y evaluación. Este resumen que presentamos de manera global nos permite dar relevancia a su valor como ayuda en el trabajo concreto, por estar nutrido de la experiencia recogida y la práctica puesta en marcha, binomio cómplice para un trabajo de tamaña envergadura.

\section{Walter Espinoza-Olcay}

Universidad Nacional Mayor de San Marcos, Lima, Perú

Contacto: walter.espinoza@unmsm.edu.pe

https://orcid.org/0000-0002-1453-8456 